\title{
Effects of estrogen receptor $\alpha$ and $\beta$ on the expression of visfatin and retinol-binding protein 4 in 3T3-L1 adipocytes
}

\author{
UN SUK JUNG $^{1}$, KANG JIN JEONG ${ }^{2}$, JAE KU KANG ${ }^{2}$, KYONGWOOK YI $^{3}$, JUNG-HO SHIN ${ }^{3}$ \\ HONG SEOG SEO ${ }^{4}$, TAK KIM ${ }^{3}$, SUN-HAENG KIM ${ }^{3}$ and JUN-YOUNG HUR ${ }^{3}$ \\ ${ }^{1}$ Department of Obstetrics and Gynecology, Konyang University Hospital, College of Medicine, \\ ${ }^{2}$ Department of Pharmacology, College of Medicine, Konyang University, Daejeon 302-718; \\ Departments of ${ }^{3}$ Obstetrics and Gynecology and ${ }^{4}$ Cardiology, College of Medicine, \\ Korea University, Seoul 152-703, Republic of Korea
}

Received April 3, 2013; Accepted July 8, 2013

DOI: $10.3892 /$ ijmm.2013.1440

\begin{abstract}
The aim of this study was to investigate the effects of estrogen and estrogen receptor $\alpha(\mathrm{ER} \alpha)$ and $\beta(\mathrm{ER} \beta)$ on the expression of visfatin and retinol-binding protein 4 (RBP4) by treating 3T3-L1 adipocytes with estradiol (E2), estrogen receptor agonists and antagonists. Mature adipocytes were exposed to E2, the ER $\alpha$ agonist, 4,4',4"-(4-propyl$[1 \mathrm{H}]$-pyrazole-1,3,5-triyl)trisphenol (PPT), the ER $\beta$ agonist, 2,3-bis(4-hydroxyphenyl)-propionitrile (DPN), E2 with the ER $\alpha$ antagonist, 1,3-bis(4-hydroxyphenyl)-4-methyl-5-[4(2-piperidinylethoxy)phenol]-1H-pyrazole dihydrochloride (MPP), and E2 with the ER $\beta$ antagonist, (5R, 11R)-5,11diethyl-5,6,11,12-tetrahydro-2,8-chrysenediol [(R,R)-THC], at various concentrations. To determine the effects of ER subtypes on the expression of adipokines, quantitative reverse transcriptase-polymerase chain reaction (qRT-PCR) and western blot analyses were performed. E2 concentrations of $10^{-5}$ and $10^{-6} \mathrm{~mol} / 1$ induced a statistically significant increase in the expression of RBP4 ( $\mathrm{P}=0.012$ and $\mathrm{P}=0.011$, respectively). In the cells treated with $10^{-5} \mathrm{~mol} / \mathrm{l} \mathrm{PPT}, \mathrm{RBP} 4$ expression significantly increased $(\mathrm{P}<0.05)$ in a dose-dependent manner. Treatment with the ER $\alpha$ antagonist, MPP $\left(10^{-5} \mathrm{~mol} / \mathrm{l}\right)$, and E2 suppressed the expression of RBP4 $(\mathrm{P}=0.032)$. However, the expression of RBP4 was not significantly altered when the cells were treated with the ER $\beta$ agonist or antagonist. The expression of visfatin was not affected by different concentrations of E2 and ERs. 17ß-estradiol significantly increased the secretion of RBP4 and upregulated RBP4 expression via $\mathrm{ER} \alpha$ but not ER $\beta$ in 3T3-L1 adipocytes. RBP4 expression was regulated by estrogen in the 3T3-L1 adipocytes and this effect was selectively mediated by ER $\alpha$.
\end{abstract}

Correspondence to: Professor Jun-Young Hur, Department of Obstetrics and Gynecology, College of Medicine, Korea University, 148 Gurodong-ro, Guro-gu, Seoul 152-703, Republic of Korea E-mail: petrow@kyuh.ac.kr

Key words: adipocytes, adipokines, visfatin, retinol-binding protein 4

\section{Introduction}

Adipose tissue is not only a simple energy store, but is increasingly being recognized as an important organ in the regulation of metabolism and pathological processes. Adipokines are a series of soluble factors secreted by adipose tissue. There are several known types of adipokines, such as relatively well known leptin, adiponectin, interleukin-6 and resistin, as well as visfatin and retinol-binding protein 4 (RBP4) (1-3). Visfatin is a 52-kDa cytokine secreted by visceral fat and its expression level in plasma increases with the severity of obesity. Visfatin exerts insulin-mimetic effects and its plasma levels increase in overweight and obese patients with metabolic syndrome $(2,4)$. RBP4 was initially thought to function only in the delivery of retinol to tissues (5). However, the transgenic overexpression of human RBP4 causes insulin resistance and glucose intolerance through a retinol-independent mechanism, whereas the normalization of serum RBP4 induces insulin sensitivity. In obese patients with type 2 diabetes mellitus, serum levels of RBP4 are increased $(1,6)$. Substances involved in the regulation of adipokine expression in adipocytes are currently being investigated. Such substances may participate in energy elevation, sugar or lipid metabolic processes and the overall process of obesity within the body.

Estrogen deficiency during menopause causes excessive visceral adipose tissue accumulation which is known to be linked to metabolic syndrome (7). Loss of ovarian function is related to both an increase in total fat and an accumulation of central fat, which increases the risk of cardiovascular and metabolic disease (8-11). Adipose tissue metabolism is directly influenced by sex hormones, particularly estrogen, and the estrogen receptor (ER) is expressed at the mRNA and protein level in human adipose tissues (12). ER $\alpha$ and ER $\beta$ are both expressed in adipose tissue and bind estrogen with different affinities $(13,14)$. The physiological role of ER $\beta$ appears to be a modulator of ER $\alpha$ activity in vitro (15). However, very little is known about the effects of the two subtypes of ERs on the expression of visfatin and RBP4.

In this study, we aimed to demonstrate the effects of estrogen via ERs on visfatin and RBP4 expression by manipulating 
the concentration of estradiol (E2) and ER $\alpha$ - and $\beta$-selective agonists and antagonists in 3T3-L1 adipocytes.

\section{Materials and methods}

Materials. We used 17 $\beta$-estradiol (1,3,5[10]-estratriene-3, $17 \beta$-diol, cell culture tested) purchased from Sigma (St. Louis, MO, USA). The ER $\alpha$ selective agonist, 4,4',4"-(4-propyl-[1H]pyrazole-1,3,5-triyl)trisphenol (PPT), the ER $\beta$ selective agonist, 2,3-bis(4-hydroxyphenyl)-propionitrile (DPN), the ER $\alpha$ selective antagonist, 1,3-bis(4-hydroxyphenyl)-4-methyl-5-[4(2-piperidinylethoxy)phenol]-1H-pyrazole dihydrochloride (MPP), and the ER $\beta$ pure antagonist and partial ER $\alpha$ agonist, (5R, 11R)-5,11-diethyl-5,6,11,12-tetrahydro-2,8-chrysenediol [(R,R)-THC], were purchased from Tocris Bioscience (Ellisville, MO, USA). Anti-mouse RBP4 and anti-mouse visfatin antibodies were obtained from R\&D Systems (Minneapolis, MN, USA). Anti-GAPDH antibody was purchased from Bio-Rad Laboratories (Hercules, CA, USA).

Cell culture. Mouse 3T3-L1 fibroblasts (American Type Culture Collection, Manassas, VA, USA) were plated at $5 \times 10^{4}$ cells in Dulbecco's modified Eagle's medium (DMEM) supplemented with $25 \mathrm{mM}$ glucose, $10 \%$ fetal bovine serum (FBS), 500 units $/ \mathrm{ml}$ penicillin and $500 \mu \mathrm{g} / \mathrm{ml}$ streptomycin (medium A) at $37^{\circ} \mathrm{C}$ in a $5 \% \mathrm{CO}_{2}$ humidified atmosphere. The cells were grown in the same medium until three days after confluence and were then differentiated into mature adipocytes by treatment with $500 \mu \mathrm{M}$ 3-isobutyl-1-methylxanthine (IBMX), $250 \mathrm{nM}$ dexamethasone and $330 \mathrm{nM}$ insulin in medium A. The cells were then incubated for two days in medium A containing $330 \mathrm{nM}$ insulin, followed by four days of incubation in medium A. The medium was changed every two days. After eight days of incubation, the intracytoplasmic accumulation of lipid droplets was observed in the fully differentiated 3T3-L1 adipocytes and they were stained with Oil Red O solution $(0.5 \%$ Oil Red O in isopropanol). For all the experiments, mature adipocytes were serum-starved for $12 \mathrm{~h}$ and then incubated with or without chemical reagents at various concentrations. At first, the cells were incubated in sterile medium containing various concentrations of E2. To modulate ER $\alpha$ and ER $\beta$ expression in adipocytes, the ER agonists, PPT or DPN, were added to the cells at several concentrations. In subsequent experiments, the ER antagonists, MPP or (R,R)-THC, were added to cells along with a constant dose of E2 for stimulation. These cells were used for the measurement of RBP4 and visfatin expression.

Assessment of cell viability and cell number. Cultured cells were detached from the culture dishes with $0.05 \%$ trypsinEDTA (Gibco BRL, Life Technologies, Merelbeke, Belgium) at $72 \mathrm{~h}$ of culture under different culture conditions. The cells were stained with trypan blue (Gibco BRL, Life Technologies) and viable cells were counted on a hemocytometer without staining.

Total RNA isolation and reverse transcription reaction. RNA was extracted and purified using an RNeasy lipid tissue mini kit as suggested by the manufacturer (Qiagen, Valencia, CA, USA). The RNA concentration was measured using a spectrophotometer $\left(\mathrm{DU}^{\circledR} 530\right.$; Beckman Coulter, Fullerton, CA, USA) and RNA quality was confirmed on agarose gels. A total
RNA sample (2 $\mu \mathrm{g} / \mathrm{sample})$ was used for cDNA synthesis in a volume of $20 \mu \mathrm{l}$ using a SuperScript ${ }^{\mathrm{TM}}$ III First-Strand Synthesis System for RT-PCR kit (Invitrogen, Milano, Italy). RNA was reverse-transcribed under the following conditions: $25 \mathrm{mM}$ $\mathrm{MgCl}_{2}, 10 \mathrm{mM}$ dNTP mix, 10X RT buffer, 0.1 M DTT, $200 \mathrm{U}$ of SuperScript $^{\mathrm{TM}}$ III (Invitrogen), $40 \mathrm{U}$ of RNaseOut and $50 \mu \mathrm{M}$ oligo(dT) primers in a final volume of $20 \mu \mathrm{l}$. The reaction was incubated at $65^{\circ} \mathrm{C}$ for $5 \mathrm{~min}$ and $50^{\circ} \mathrm{C}$ for $50 \mathrm{~min}$ and the enzyme was then heat-inactivated at $85^{\circ} \mathrm{C}$ for $5 \mathrm{~min}$. Four microliters of the reaction product were used for quantitative PCR.

Quantitative PCR. Quantitative PCR was used to quantify the mRNA expression of RBP4 and visfatin. The expression was normalized using the GAPDH housekeeping gene product as an internal reference. The primers and probes were designed for mouse RBP4 and visfatin using Primer Express ${ }^{\circledR}$ Software version 2.0 (Applied Biosystems, Foster City, CA, USA). RBP4 and visfatin mRNA levels were quantified using TaqMan Real-Time PCR with an ABI 7700 system (Applied Biosystems). Gene-specific probes and primer pairs for RBP4 (Assays-on-Demand, Mm00803264_m1; Applied Biosystems) and visfatin (Assays-on-Demand, Mm00451938_m1; Applied Biosystems) were used. For each probe/primer set, a standard curve was generated, which was confirmed to increase linearly with increasing amounts of cDNA. The amplification conditions were $2 \mathrm{~min}$ at $50^{\circ} \mathrm{C}, 10 \mathrm{~min}$ at $95^{\circ} \mathrm{C}$ and a two-step cycle of $95^{\circ} \mathrm{C}$ for $15 \mathrm{sec}$ and $60^{\circ} \mathrm{C}$ for $60 \mathrm{sec}$ for a total of 45 cycles.

Western blot analysis. The cells were lysed using a buffer containing $50 \mathrm{mM}$ HEPES (pH 7.5), $150 \mathrm{mM} \mathrm{NaCl}, 1.5 \mathrm{mM}$ $\mathrm{MgCl}_{2}, 1 \mathrm{mM}$ EDTA, $10 \%$ glycerol, $1 \%$ Triton X-100 and a mixture of protease inhibitors [aprotinin, phenylmethyl sulfonyl fluoride (PMSF) and sodium orthovanadate]. Equal amounts of total protein were resolved on a $12 \%$ SDS-polyacrylamide gel and proteins were transferred onto a nitrocellulose membrane. After blocking (TBS, $0.1 \%$ Tween-20) at $4^{\circ} \mathrm{C}$ overnight, the membranes were incubated with primary antibodies for antimouse RBP4 (dilution 1:1000) or anti-mouse visfatin (dilution 1:1000) for $2 \mathrm{~h}$ followed by incubation with secondary antibodies linked to HRP, anti-mouse GAPDH (dilution 1:2000). Immunoreactive proteins were visualized by chemiluminescence using SuperSignal ${ }^{\circledR}$ West Dura Extended Duration Substrate (Pierce Chemical Co., Rockford, IL, USA) and a Fujifilm Luminescent Image Analyzer LAS-3000 with a chargecoupled device camera (Science Imaging Scandinavia AB).

Statistical analysis. To compare the mRNA expression levels of RBP4 and visfatin in adipocytes, analysis of variance (ANOVA) with a post-hoc Dunnett's test was used. Data are presented as the means \pm standard error of the mean. To evaluate the presence of a correlation, Pearson's correlation coefficient and linear regression analysis were used. Null hypotheses of no difference were rejected if $\mathrm{P}<0.05$. All statistical analyses were performed using the SPSS statistical package version 10.0 (SPSS, Inc., Chicago, IL, USA).

\section{Results}

Effects of estradiol on expression of RBP-4 and visfatin in adipocytes. To investigate the effects of $\mathrm{E} 2$ on the expression 

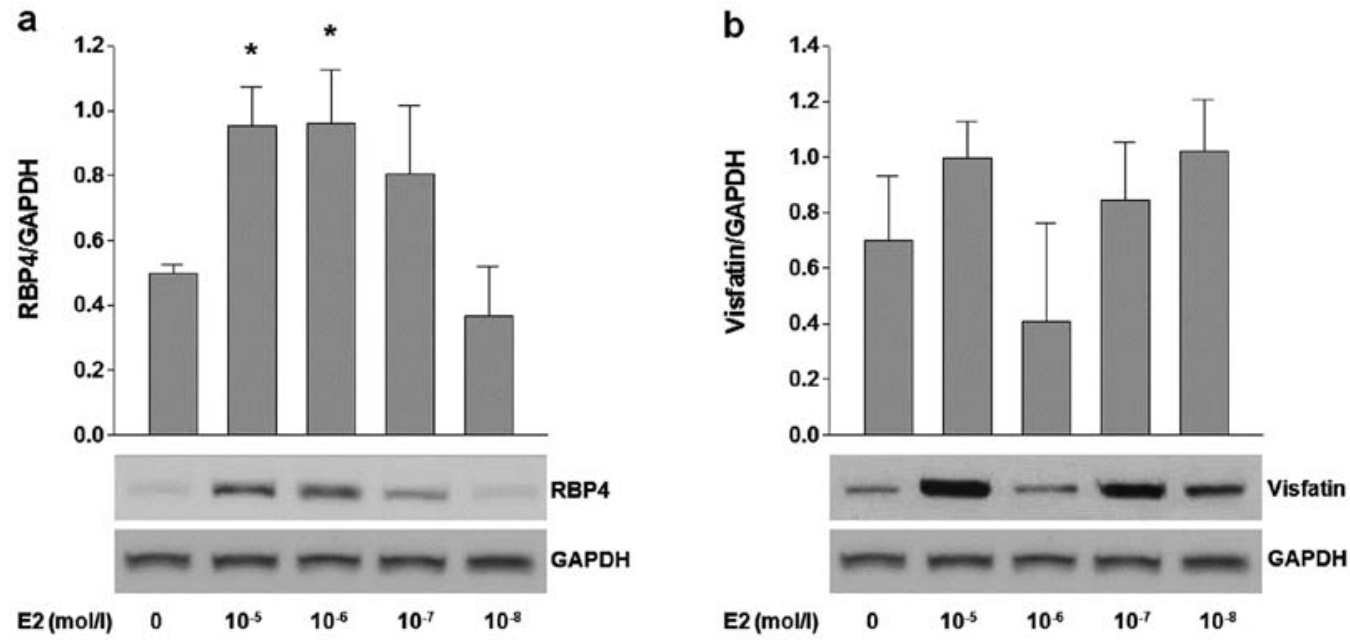

Figure 1. Effects of estradiol (E2) on the protein and mRNA expression of (a) retinol-binding protein 4 (RBP4) and (b) visfatin. 3T3-L1 adipocytes were incubated in medium containing E2 at the indicated range of concentrations for $24 \mathrm{~h}$. Total RNA was extracted and (a) RBP4 and (b) visfatin mRNA levels were measured using quantitative reverse transcription PCR. Western blot analysis was used to measure the protein expression of estrogen receptor (ER) in 3T3-L1 adipocytes under the same conditions. Data are the means \pm SD of three independents experiments. Results were analyzed by ANOVA and post-hoc Dunnett's test. "P<0.05 vs. control; GAPDH, glyceraldehyde 3-phosphate dehydrogenase.
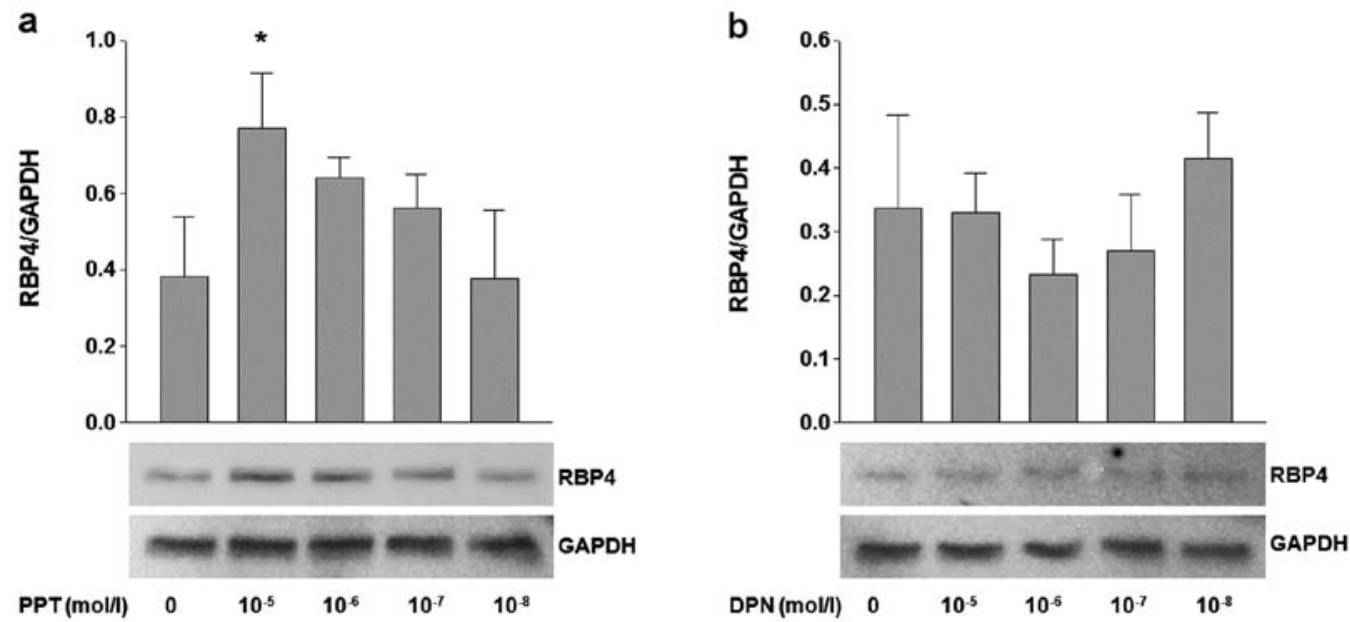

Figure 2. Effects of estrogen receptor (ER) agonists on the protein and mRNA expression of retinol-binding protein 4 (RBP4) in 3T3-L1 adipocytes. The 3T3-L1 adipocytes were incubated in medium containing (a) 4,4',4"-(4-propyl-[1H]-pyrazole-1,3,5-triyl)trisphenol (PPT) and (b) 2,3-bis(4-hydroxyphenyl)propionitrile at the indicated concentrations for $24 \mathrm{~h}$. Total RNA was extracted and RBP4 mRNA levels were measured using reverse transcription PCR. Western blot analysis was used to measure the protein expression of RBP4 in 3T3-L1 adipocytes under the same conditions. Data are the means \pm SD of three independent experiments. Results were analyzed by ANOVA and the post-hoc Dunnett's test. "P<0.05 vs. control; GAPDH, glyceraldehyde 3-phosphate dehydrogenase.

of RBP4 and visfatin, 3T3-L1 adipocytes were treated with various concentrations $\left(10^{-5}-10^{-9} \mathrm{~mol} / \mathrm{l}\right)$ of E2. Treatment with high concentrations $\left(10^{-5}\right.$ and $\left.10^{-6} \mathrm{~mol} / \mathrm{l}\right)$ of E2 significantly increased the RBP4 mRNA levels $(\mathrm{P}=0.012, \mathrm{P}=0.011$, respectively), as well as RBP4 protein expression (Fig. 1a). However, the expression of visfatin was not influenced by any tested concentration of E2 (Fig. 1b).

Effects of ER $\alpha$ and ER $\beta$ agonists (PPT and DPN) on the expression of RBP4 and visfatin. The adipocytes were treated with various concentrations of PPT (ER $\alpha$ agonist) and DPN (ER $\beta$ agonist) to investigate the effects of $E R \alpha$ and $E R \beta$ on the expression of RBP4 and visfatin. The cells treated with $10^{-5} \mathrm{~mol} / \mathrm{l}$ PPT showed a significant and dose-dependent increase in RBP4 mRNA $(\mathrm{P}<0.05)$ and protein expression
(Fig. 2a). On the other hand, the adipocytes treated with DPN showed no difference in expression (Fig. 2b). Of note, the mRNA and protein expression of visfatin was not influenced by treatment with PPT and DPN (Fig. 3a and b).

Effects of ER $\alpha$ and ER $\beta$ antagonists [MPP and $(R, R)-T H C$ ] on the expression of RBP4 and visfatin. In parallel with the ER agonist experiment, ER antagonists [MPP and (R,R)-THC] were used to verify the functions of ER subtypes in fat cells. The aim of this experiment was to isolate the effects of each ER subtype. The cells were treated simultaneously with a fixed concentration of E2 $\left(10^{-7} \mathrm{~mol} / \mathrm{l}\right)$ to provide an appropriate stimulus. Treatment with high concentrations $\left(10^{-5} \mathrm{~mol} / \mathrm{l}\right)$ of MPP and E2 $\left(10^{-7} \mathrm{~mol} / \mathrm{l}\right)$ resulted in the reduced expression of $\mathrm{RBP} 4$ at the mRNA and protein level $(\mathrm{P}=0.032)$. No significant 

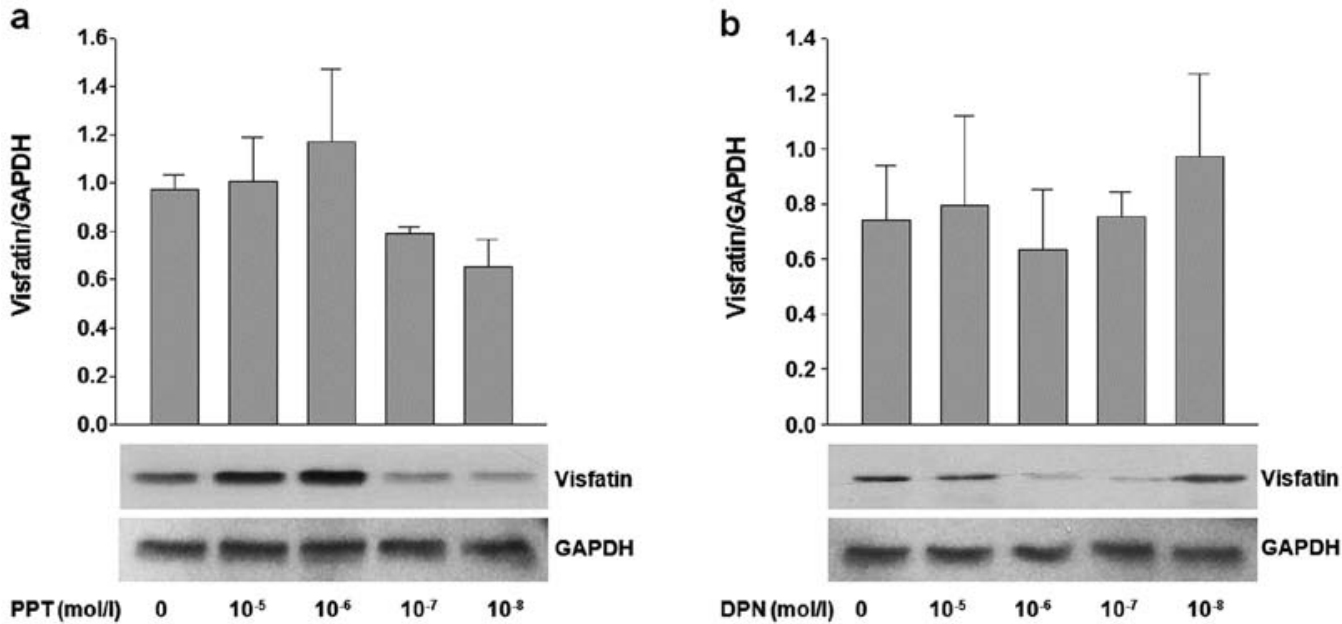

Figure 3. Effects of estrogen receptor (ER) agonists on protein and mRNA expression of visfatin in 3T3-L1 adipocytes. The 3T3-L1 adipocytes were incubated in medium containing (a) 4,4',4"-(4-propyl-[1H]-pyrazole-1,3,5-triyl)trisphenol (PPT) and (b) 2,3-bis(4-hydroxyphenyl)-propionitrile at the indicated concentrations for $24 \mathrm{~h}$. Total RNA was extracted and visfatin mRNA levels were measured using reverse transcription PCR. Western blot analysis was used to measure the protein expression of visfatin in 3T3-L1 adipocytes under the same conditions. Data are the means \pm SD of three independent experiments. Results were analyzed by ANOVA and the post-hoc Dunnett's test. GAPDH, glyceraldehyde 3-phosphate dehydrogenase.
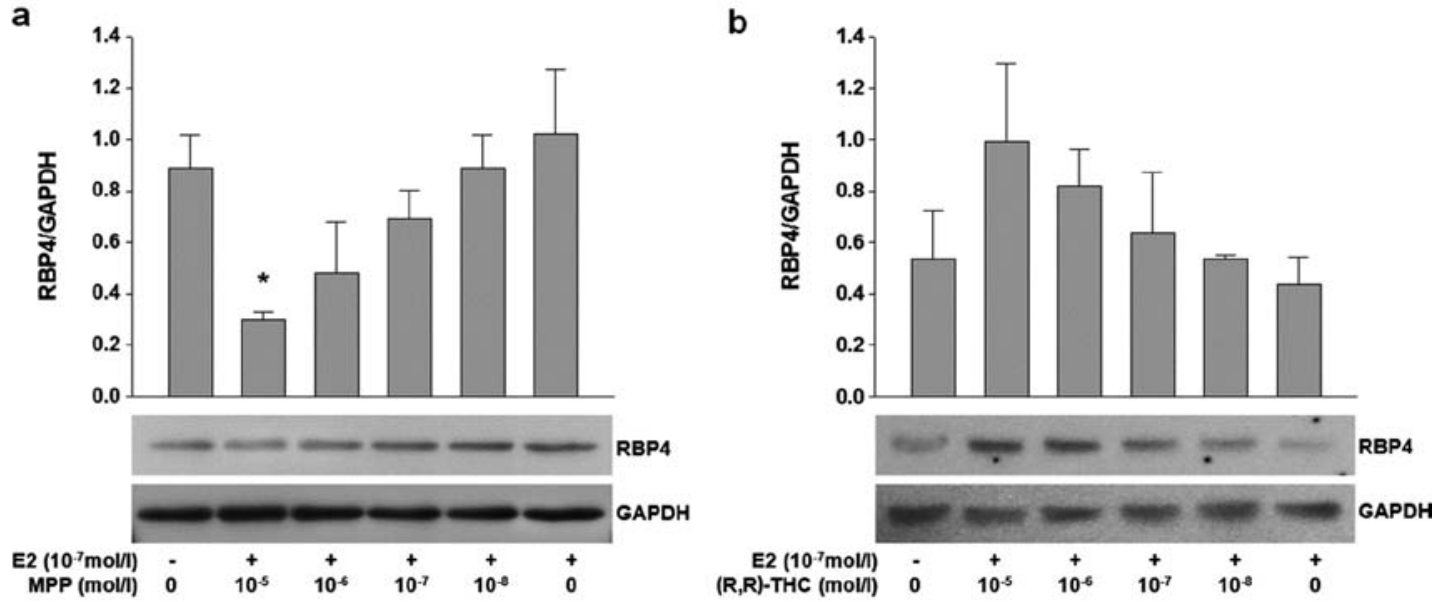

Figure 4. Effects of estrogen receptor (ER) antagonists on protein and mRNA expression of retinol-binding protein 4 (RBP4) in 3T3-L1 adipocytes.The 3T3-L1 adipocytes were incubated in medium containing (a) 1,3-bis(4-hydroxyphenyl)-4-methyl-5-[4-(2-piperidinylethoxy)phenol]-1H-pyrazole dihydrochloride (MPP) and (b) (5R, 11R)-5,11-diethyl-5,6,11,12-tetrahydro-2,8-chrysenediol [(R,R)-THC] in conjunction with E2 at the indicated concentrations for $24 \mathrm{~h}$. Total RNA was extracted from the adipocytes and the RBP4 mRNA levels were measured using quantitative reverse transcription PCR. Western blot analysis was used to measure protein expression of RBP4 in 3T3-L1 adipocytes under the same conditions. Data are the means \pm SD of three independent experiments. Results were analyzed by ANOVA and the post-hoc Dunnett's test. " $\mathrm{P}<0.05$ vs. control; GAPDH, glyceraldehyde 3-phosphate dehydrogenase.

change in the mRNA level of RBP4 was observed following treatment with variable concentrations of (R,R)-THC (Fig. 4a and $b)$. There was no significant change in the expression of visfatin upon treatment with various concentrations of MPP or (R,R)-THC (Fig. 5a and b).

\section{Discussion}

In this study, we evaluated the effects of $17 \beta$-estradiol on RBP4 and visfatin expression in 3T3-L1 adipocytes. RBP4 mRNA expression and protein production was increased in a dose-dependent manner in adipocytes by estradiol. RBP4 does not reach adult plasma levels until puberty, after which plasma levels are changeable, based on the menstrual cycle (16-18). This variation in the plasma RBP level appears to correlate with peak levels of estradiol and menopausal status in females. Previous studies have reported that plasma RBP4 levels in post-menopausal women are higher than those in pre-menopausal women, which is associated with insulin resistance $(19,20)$. After menopause, women develop increased amounts of visceral fat due to fat redistribution. RBP4 expression is highly elevated, not just in serum, but also in visceral fat, and serum RBP4 protein levels are considered a marker of intra-abdominal fat mass (21). Thus, we initially assumed that a correlation may exist between specific adipokines in visceral fat and estrogen. ER $\alpha$ and $\beta$ densities are more dependent on the location of adipose deposition than on gender, with visceral depots showing higher mRNA densities (22). Our results demonstrated that $17 \beta$-estradiol significantly increased the secretion of RBP4 and upregulated the expession of RBP4 
a

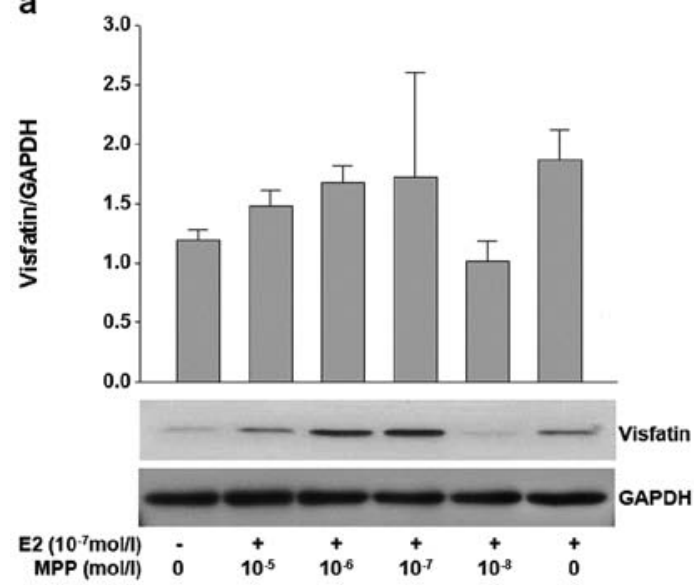

b

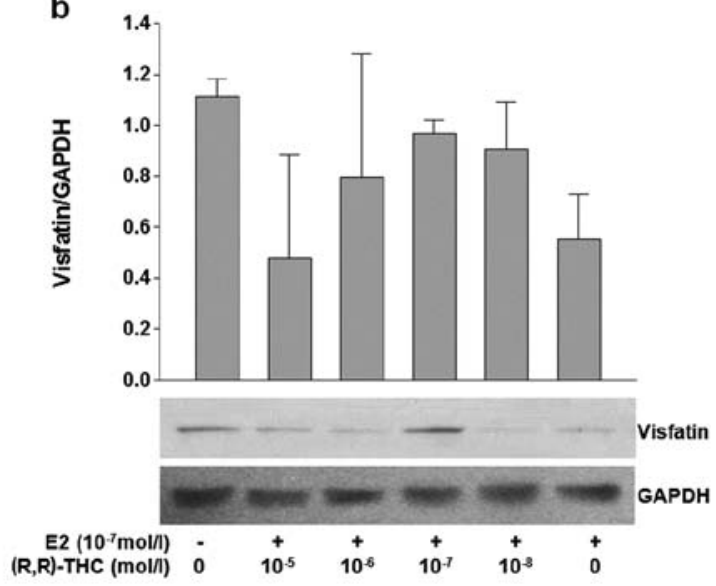

Figure 5. Effects of estrogen receptor (ER) antagonists on protein and mRNA expression of visfatin in 3T3-L1 adipocytes. The 3T3-L1 adipocytes were incubated in medium containing (a) 1,3-bis(4-hydroxyphenyl)-4-methyl-5-[4-(2-piperidinylethoxy)phenol]-1H-pyrazole dihydrochloride (MPP) and (b) $(5 \mathrm{R}, 11 \mathrm{R})-5,11$-diethyl-5,6,11,12-tetrahydro-2,8-chrysenediol [(R,R)-THC] in conjunction with E2 at the indicated concentrations for 24 h. Total RNA was extracted from the adipocytes and visfatin mRNA levels were measured using quantitative reverse transcription PCR. Western blot analysis was used to measure the protein expression of visfatin in 3T3-L1 adipocytes under the same conditions. Data are the means \pm SD of three independent experiments. Results were analyzed by ANOVA and the post-hoc Dunnett's test. GAPDH, glyceraldehyde 3-phosphate dehydrogenase.

in 3T3-L1 adipocytes, which is consistent with the results of previous studies $(23,24)$.

In a previous study, Janke et al reported that RBP4 gene expression in adipose tissue was decreased in obese menopausal subjects and that there were no differences in serum RBP4 levels among lean, overweight and obese menopausal subjects (25). However, their experiment used human subcutaneous adipose tissue in vivo and the RBP4 level is not related to subcutaneous fat mass. The serum RBP4 level does not correlate with the subcutaneous fat diameter, but rather with the visceral fat diameter (26).

The reason estrogen significantly increases RBP4 expression in adipose tissues is unclear. Vitamin A (retinol) is taken up by peripheral tissue, such as the genital tracts in the form of free retinol by passive diffusion based on the concentration gradient between the blood and cytosol. Retinol is therefore thought to play a pivotal role in the female reproductive organs. In addition, estrogen itself appears to control retinoic acid biosynthesis. Estrogen has been shown to markedly increase the cellular RBP4 mRNA content in rat vagina and uterus tissues, which participate in the uptake and/or intracellular metabolism of retinol (27). We found that estrogen significantly upregulated the expression of RBP4 in 3T3-L1 adipocytes. Thus, the estrogen-induced upregulation of RBP4 expression in adipose tissue is expected to result in a shift in the equilibrium of retinoic acid in the reproductive organs. Our results suggest that estrogen mediates retinoic acid metabolism by the regulation of RBP4 expression in adipose tissue. The systemic deficiency of serum estrogen may activate a specific regulatory process and consequently, may induce the overexpression of RBP4 through ER in visceral adipocytes. These data, together with our finding that estrogen stimulates RBP4 expression in adipocytes, this process may be partially due to a decrease in serum estrogen levels after menopause.

Visfatin may play an important role in adipocyte metabolism in association with metabolic syndrome-related diseases. Visfatin is regulated by conditions associated with metabolic syndrome and visfatin mRNA expression is regulated by sex hormones in 3T3-L1 pre-adipocytes (28). The estriol treatment of 3T3-L1 cells has been shown to increase visfatin gene expression, but estradiol had insignificant effects on visfatin gene expression (29). These results are partly consistent with our finding that visfatin was not directly influenced by estrodiol in 3T3-L1 adipocytes.

Estradiol selectively influences adipose tissue, according to the type of adipokine. $\mathrm{ER} \alpha$ and $\beta$ control the expression of leptin in different ways (30). However, our results verified that adipokines can be influenced independently by ER $\alpha$ without being affected by ER $\beta$. There are many existing studies on the effect of sex hormones on adipokine expression, but the results of these studies differ according to the type of adipokine or the experimental design (31-33). These differences suggest that the pathway may be dependent on adipokine type and may be established through the specific ER type. However, a comprehensive analysis of the effects of steroidal hormones on adipokine expression is warranted.

We found that estrogen significantly increased RBP4 expression via ER $\alpha$ in 3T3-L1 adipocytes without influencing visfatin expression, suggesting a novel role for $\mathrm{ER} \alpha$ in the regulation of RBP4 expression. To the best of our knowledge, this is the first demonstration that $17 \beta$-estradiol significantly increases the secretion of RBP4 and upregulates RBP4 expression via $\mathrm{ER} \alpha$, but not $\mathrm{ER} \beta$, in $3 \mathrm{~T} 3-\mathrm{L} 1$ adipocytes. RBP4 may have a specific function in visceral fat redistribution in menopausal women. Through the control of sex hormones in menopausal women, the regulation of RBP4 expression in adipose tissue may potentially inhibit visceral fat redistribution and ultimately protect post-menopausal women from obesity-related diseases. Further in vivo studies are required to investigate the link between RBP4 expression and estrogen, while considering the effects of estrogen status, including the menstrual cycle. In addition, the results of this study need to be clinically verified. The development of novel therapeutics for metabolic syndrome-related diseases will require further understanding of the correlation between the effects of estrogen and adipokines. 


\section{Acknowledgements}

This study was supported in part by the Konyang University Myunggok Research Fund of 2009.

\section{References}

1. Yang Q, Graham TE, Mody N, et al: Serum retinol binding protein 4 contributes to insulin resistance in obesity and type 2 diabetes. Nature 436: 356-362, 2005.

2. Fukuhara A, Matsuda M, Nishizawa M, et al: Visfatin: a protein secreted by visceral fat that mimics the effects of insulin. Science 307: 426-430, 2005

3. Klein J, Perwitz N, Kraus D and Fasshauer M: Adipose tissue as source and target for novel therapies. Trends Endocrinol Metab 17: 26-32, 2006.

4. Filippatos TD, Derdemezis CS, Kiortsis DN, Tselepis AD and Elisaf MS: Increased plasma levels of visfatin/pre-B cell colonyenhancing factor in obese and overweight patients with metabolic syndrome. J Endocrinol Invest 30: 323-326, 2007.

5. Tilg $\mathrm{H}$ and Moschen AR: Adipocytokines: mediators linking adipose tissue, inflammation and immunity. Nat Rev Immunol 6 : 772-783, 2006

6. Masaki T, Anan F, Tsubone T, et al: Retinol binding protein 4 concentrations are influenced by renal function in patients with type 2 diabetes mellitus. Metabolism 57: 1340-1344, 2008.

7. Wajchenberg BL: Subcutaneous and visceral adipose tissue: their relation to the metabolic syndrome. Endocr Rev 21: 697-738, 2000

8. Bjorntorp P: Adipose tissue distribution and function. Int $\mathrm{J}$ Obes 15 (Suppl 2): 67-81, 1991

9. Tchernof A and Poehlman ET: Effects of the menopause transition on body fatness and body fat distribution. Obes Res 6 : 246-254, 1998

10. Carr MC: The emergence of the metabolic syndrome with menopause. J Clin Endocrinol Metab 88: 2404-2411, 2003.

11. Tchernof A, Desmeules A, Richard C, et al: Ovarian hormone status and abdominal visceral adipose tissue metabolism. J Clin Endocrinol Metab 89: 3425-3430, 2004

12. Mizutani T, Nishikawa Y, Adachi H, et al: Identification of estrogen receptor in human adipose tissue and adipocytes. J Clin Endocrinol Metab 78: 950-954, 1994.

13. Kuiper GG, Carlsson B, Grandien K, et al: Comparison of the ligand binding specificity and transcript tissue distribution of estrogen receptors alpha and beta. Endocrinology 138: 863-870, 1997.

14. Pedersen SB, Bruun JM, Hube F, Kristensen K, Hauner H and Richelsen B: Demonstration of estrogen receptor subtypes alpha and beta in human adipose tissue: influences of adipose cell differentiation and fat depot localization. Mol Cell Endocrinol 182: 27-37, 2001.

15. Liu MM, Albanese C, Anderson CM, et al: Opposing action of estrogen receptors alpha and beta on cyclin D1 gene expression. J Biol Chem 277: 24353-24360, 2002.

16. Vahlquist A, Rask L, Peterson PA and Berg T: The concentrations of retinol-binding protein, prealbumin, and transferrin in the sera of newly delivered mothers and children of various ages. Scand J Clin Lab Invest 35: 569-575, 1975.
17. Michaelsson G, Vahlquist A, Juhlin L, Mellbin T and Bratt L: Zinc and vitamin A: serum concentrations of zinc and retinolbinding protein (RBP) in healthy adolescents. Scand J Clin Lab Invest 36: 827-832, 1976.

18. Vahlquist A, Johnsson A and Nygren KG: Vitamin A transporting plasma proteins and female sex hormones. Am J Clin Nutr 32: 1433-1438, 1979.

19. Suh JB, Kim SM, Cho GJ, Choi KM, Han JH and Taek Geun H: Elevated serum retinol-binding protein 4 is associated with insulin resistance in older women. Metabolism 59: 118-122, 2010.

20. An C, Wang H, Liu X, et al: Serum retinol-binding protein 4 is elevated and positively associated with insulin resistance in postmenopausal women. Endocr J 56: 987-996, 2009.

21. Kloting N, Graham TE, Berndt J, et al: Serum retinol-binding protein is more highly expressed in visceral than in subcutaneous adipose tissue and is a marker of intra-abdominal fat mass. Cell Metab 6: 79-87, 2007.

22. Rodriguez-Cuenca S, Monjo M, Proenza AM and Roca P: Depot differences in steroid receptor expression in adipose tissue: possible role of the local steroid milieu. Am J Physiol Endocrinol Metab 288: E200-E207, 2005.

23. Tan BK, Chen J, Lehnert H, Kennedy R and Randeva HS: Raised serum, adipocyte, and adipose tissue retinol-binding protein 4 in overweight women with polycystic ovary syndrome: effects of gonadal and adrenal steroids. J Clin Endocrinol Metab 92: 2764-2772, 2007.

24. Whitman MM, Harnish DC, Soprano KJ and Soprano DR: Retinol-binding protein mRNA is induced by estrogen in the kidney but not in the liver. J Lipid Res 31: 1483-1490, 1990.

25. Janke J, Engeli S, Boschmann M, et al: Retinol-binding protein 4 in human obesity. Diabetes 55: 2805-2810, 2006.

26. Tschoner A, Sturm W, Engl J, et al: Retinol-binding protein 4, visceral fat, and the metabolic syndrome: effects of weight loss. Obesity (Silver Spring) 16: 2439-2444, 2008.

27. Matsuda M, Masui F and Mori T: Neonatal estrogenization leads to increased expression of cellular retinol binding protein 2 in the mouse reproductive tract. Cell Tissue Res 316: 131-139, 2004.

28. MacLaren R, Cui W and Cianflone K: Visfatin expression is hormonally regulated by metabolic and sex hormones in 3T3-L1 pre-adipocytes and adipocytes. Diabetes Obes Metab 9: 490-497, 2007.

29. Zhou J and Seidel ER: Estrogens induce visfatin expression in 3T3-L1 cells. Peptides 31: 271-274, 2010.

30. Yi KW, Shin JH, Seo HS, et al: Role of estrogen receptor-alpha and -beta in regulating leptin expression in 3T3-L1 adipocytes. Obesity (Silver Spring) 16: 2393-2399, 2008.

31. Watanobe $\mathrm{H}$ and Suda T: A detailed study on the role of sex steroid milieu in determining plasma leptin concentrations in adult male and female rats. Biochem Biophys Res Commun 259: 56-59, 1999.

32. Kristensen K, Pedersen SB and Richelsen B: Regulation of leptin by steroid hormones in rat adipose tissue. Biochem Biophys Res Commun 259: 624-630, 1999.

33. Chen YH, Lee MJ, Chang HH, Hung PF and Kao YH: 17 beta-estradiol stimulates resistin gene expression in 3T3-L1 adipocytes via the estrogen receptor, extracellularly regulated kinase, and CCAAT/enhancer binding protein-alpha pathways. Endocrinology 147: 4496-4504, 2006. 